\title{
DIEGO GUILLÉN DE ÁVILA, AUTOR Y TRADUCTOR DEL SIGLO XV
}

MARÍA ElVIRA ROCA BAREA

Consejería de Educación y Ciencia de la Junta de Andalucía

Diego Guillén de Ávila, hijo de Pero Guillén de Segovia, es un autor poco conocido cuya vida transcurrió en la última parte del siglo XV, y alcanzó al menos la segunda década del siguiente. De su trabajo conservamos tres traducciones y tres obras originales, una de ellas de atribución dudosa. Vertió al castellano el tratado militar de Frontino Stratagemata, los escritos herméticos de Hermes Trismegisto que Marsilio Ficino había traducido al latín y la Historia de Herodiado, a partir de la versión latina de Angelo Poliziano. Su actividad como traductor, por tanto, no es nada despreciable. Son fruto original de su ingenio un Panegírico a la reina Isabel I, que conviene recordar tras el quinto centenario de su muerte, así como otro dedicado a don Alonso Carrillo, arzobispo de Toledo. Se le atribuye además una pieza teatral, la Égloga interlocutoria.

La crítica no ha prestado mucha atención a nuestro autor. Nicolás Antonio menciona a Diego Guillén como autor de la traducción de Frontino ${ }^{1}$ y también le dedica algunos párrafos Pascual Gayangos en sus Adiciones a la Historia de la literatura española de George Ticknor ${ }^{2}$. Gayangos considera que «quizás deba atribuirse a este mismo autor una Égloga en coplas de arte mayor intitulada: Égloga interlocutoria: graciosa y por gentil estilo nuevamente trobada por Diego de Ávila, dirigida al muy ilustrissimo Gran Capitán» ${ }^{3}$. Es con diferencia Amador de los Ríos quien más espacio le dedica, comentando sus obras y sus traducciones ${ }^{4}$. Cayetano A. Barrera nombra en su Catálogo a Diego Gui-

${ }^{1}$ Nicolás Antonio, Bibliotheca Hispana Nova, 2 vols., Madrid, Visor, 1996, I, pág. 287. Es reimpresión de la edición en español de 1788.

${ }^{2}$ George Ticknor, Historia de la Literatura Española, Pascual Gayangos, ed. y trad., 4 vols., Madrid, Rivadeneyra, 1854, III, pág. 460.

${ }^{3}$ Pascual Gayangos, op. cit., pág. 309.

${ }^{4}$ José Amador de los Ríos, Historia crítica de la literatura española, 7 vols., Madrid, Imprenta de Joaquín Muñoz, 1865, VII, págs. 273-279. 
llén de Ávila, de quien dice que heredó el talento poético de su padre, sin mencionar las traducciones ${ }^{5}$. Sus datos parecen tomados de Gayangos. Antonio Palau y Dulcet afirma que Diego Guillén estuvo en Roma y allí cobró afición a los estudios clásicos y tradujo los libros teosóficos atribuidos a Hermes Trimegisto, y el tratado de Frontino ${ }^{6}$. Le atribuye además los dos Panegíricos y la Égloga interlocutoria.

De la vida de Diego Guillén de Ávila sabemos muy poco. Fue hijo de Pero Guillén de Segovia, el autor de La gaya ciencia y uno de los mejores poetas de la segunda mitad del siglo XV, nacido en 1413 en Sevilla ${ }^{7}$. José María Viña Liste afirma que Diego Guillén debió nacer antes de $1483^{8}$. Evidentemente debió ser mucho antes, en los años centrales del siglo, pues en esa fecha su padre contaba ya 70 años. Dada la escasez de los datos que poseemos sobre Diego, tomaremos la vida de su padre, algo mejor conocida, como referente para establecer al menos unas coordenadas biográficas mínimas, porque, como veremos, una parte importante de la producción literaria de Diego Guillén está relacionada con su padre. Para comprender la actividad intelectual de Diego es imprescindible tener en cuenta su relación con el arzobispo Carrillo, y con Gómez Manrique y el círculo literario que se creó en torno a ambos personajes, al cual había pertenecido el padre. Pensamos que la obra literaria y de traducción del hijo puede considerarse una continuación o consecuencia de la labor literaria de este grupo. En efecto, Diego dedicará un Panegírico al arzobispo de Toledo en agradecimiento a los grandes beneficios que de él recibió, y traducirá los textos herméticos de Hermes Trimegisto para Gómez Manrique, que fue capitán del belicoso arzobispo entre 1462 y 1474 aproximadamente, y luego, en 1475, fue nombrado por los reyes corregidor de Toledo.

Pero Guillén aparece habitualmente mencionado como Pero Guillén de Segovia, aunque era sevillano. En los manuscritos encontramos casi siempre Pero Guillén, sin más. En tres casos se especifica de Sebilla, en los poemas 23, 27 y 29, según la edición de Carlos Moreno Hernández ${ }^{9}$. En el poema 23, el de los Doce estados, se añade, vecino de Segovia. La mención Pero Guillén de Segovia es del Cancionero General de Hernando del Castillo en $1511^{10}$. A la

${ }^{5}$ Cayetano A. Barrera y Leirado, Catálogo biográfico-bibliográfico del teatro antiguo español, Madrid, Rivadeneyra, 1860, pág. 181.

${ }^{6}$ Antonio Palau y Dulcet, Manual del librero hispanoamericano, 28 vols., Barcelona, Lib. Anticuaria, 1948, I, pág. 581.

${ }^{7}$ Carlos Moreno Hernández, ed., Obra poética de Pero Guillén, Madrid, Fundación Universitaria Española, 1989, pág. 315.

8 José María Viña Liste, Cronología de la literatura española, 4 vols., Madrid, Cátedra, 1991, I, pág. 158.

${ }^{9}$ Carlos Moreno Hernández, op. cit, págs. 227, 306 y 345.

${ }^{10}$ Hernando del Castillo, Cancionero General según edición de 1511, con apéndice de lo añadido en las de 1527, 1540 y 1557, Madrid, Sociedad de Bibliófilos Españoles, 1882, pág. 205. 
ciudad de Segovia estuvo Diego Guillén vinculado, y puede que naciera allí, pues en documento que se conserva en las Actas Capitulares de la catedral de Palencia con fecha del 5 de marzo de 1506, se menciona a Diego Guillén, clerigo de la diocesis de Segovia (fols. 134v-135r).

No hemos hallado explicación alguna al de Ávila con que firma Diego varias veces. Nos consta que estuvo relacionado con las ciudades de Palencia, Segovia y Roma, pero no sabemos cuál es su vínculo con Ávila. En cualquier caso, este se estableció por nacimiento o en la época de juventud, ya que el primer documento que firma nuestro autor en 1483, lo hace como Diego Guillén de Ávila. Amador de los Ríos afirma que sin duda nació en Ávila, pero no justifica esta afirmación de ningún modo ${ }^{11}$. Tampoco Julián Zarco Cuevas da razones cuando afirma que es «Diego Guillén de Segovia o de Ávila, natural de Segovia» ${ }^{12}$.

El padre de Diego Guillén de Ávila es un claro representante del gremio de los funcionarios cultos del siglo XV. Pero Guillén fue poeta de cierta fortuna y dejó una obra no pequeña ${ }^{13}$. Escribió Los siete salmos penitenciales trovados ${ }^{14}$ y otros poemas, así como unos Hechos de don Alonso Carrillo, que acompañan la dedicatoria de La gaya ciencia ${ }^{15}$. Sus poemas aparecen en varios cancioneros, y hay uno incluso que lleva su nombre. Gómez Manrique le llama gran trovador ${ }^{16}$. Su producción poética, sin embargo, estuvo dispersa hasta su edición completa en 1989 por Carlos Moreno Hernández.

De la biografía de Pero Guillén conocemos dos etapas separadas por un largo periodo de oscuridad: una juventud de poeta cortesano bien relacionado y exitoso; otra de pobreza y desdichas; y una tercera al servicio del arzobispo Carrillo. Así lo declara él mismo en sus versos ${ }^{17}$. La exitosa etapa juvenil debió transcurrir en los días del reinado de Juan II y privanza de don Álvaro de Luna. Probablemente Diego Guillén nació en esta época. En la corte, el padre tuvo amistad con Juan de Mena y el Marqués de Santillana, no obstante ser

11 José Amador de los Ríos, op. cit., pág. 276.

12 Julián Zarco Cuevas, Catálogo de manuscritos castellanos de la Real Biblioteca de El Escorial, 3 vols., Madrid, Real Academia de la Historia, 1924, I, pág. 65.

${ }^{13}$ Nicolás Antonio, op. cit., pág. 249.

${ }^{14}$ Marcelino Menéndez Pelayo, ed., Antología de poetas líricos castellanos, 10 vols., Buenos Aires, Editorial Ideas, 1943, III, págs. 133-165

${ }^{15}$ Hay dos ediciones disponibles: José María Casas Homs, ed., La Gaya Ciencia de Pero Guillén, Madrid, CSIC, 1962; Eloy Benito Ruano, ed., Hechos del Arzobispo de Toledo D. Alonso Carrillo de Pero Guillén, Barcelona, Instituto de Historia Medieval de España, 1968.

${ }^{16}$ Lo menciona fray Jerónimo de Olivares en su continuación al Tratado de vicios y virtudes de Juan de Mena. Véase Juan de Mena, Todas las obras del famosísimo poeta Juan de Mena con la glosa de Fernán Núñez sobre las Trescientas, agora nuevamente corregidas y enmendadas, Amberes, Martín Nuncio, 1552 (Microform, col. 18).

${ }^{17}$ Carlos Moreno Hernández, op. cit., pág. 291. 
Pero Guillén partidario declarado de don Álvaro de Luna ${ }^{18}$. La condena y ejecución del valido caído en desgracia en 1453 ocurrieron cuando Guillén padre tenía 40 años. Tras un decenio en la más amarga pobreza, Pero Guillén entra al servicio de don Alonso Carrillo. Amador de los Ríos, uno de los pocos autores que dedica varios párrafos a Diego Guillén, considera que este debió criarse y educarse bajo la protección del arzobispo ${ }^{19}$. Es probable que así fuera, pues, cuando entra al servicio de Alonso Carrillo, Pero Guillén tiene todavía hijos pequeños a su cargo, según él mismo confiesa ${ }^{20}$.

No sabemos en qué circunstancias abandona Pero Guillén la corte, pero algo pudo tener que ver con ello un Dezir que fizo Pero Guillén sobre la muerte de don Álvaro de Luna ${ }^{21}$. Con él pretendía justificar al Condestable de Castilla y Maestre de Santiago de los cargos de los que fue acusado y por los que fue condenado. En cualquier caso, Guillén padre estuvo en el bando de don Álvaro y su caída probablemente lo arrastró consigo. La familia vive años negros en la más triste pobreza y Pero Guillén se ve obligado a ganarse el sustento durante más de 10 años copiando escrituras ajenas, de manera que la infancia de Diego Guillén debió ser bastante dura. La suerte de Pero Guillén cambió cuando, ya muy mermadas las facultades de la vista y con unos 50 años a cuestas, escribe dos Suplicaciones a don Alonso Carrillo pidiendo su protección, que finalmente obtendría. Afirma verse tan desamparado de bienes que apenas puede mantener sus fijos menudos ${ }^{22}$. Por esta afirmación suponemos que Diego era en torno a 1463 un niño o un muchacho. La situación económica de la familia Guillén no debió de ser nunca muy holgada. Años más tarde, muerto Carrillo y perdida por lo tanto su protección, los hijos de Pero Guillén, Diego y posiblemente otro hermano con el mismo nombre que su padre, siguen pasando dificultades en Palencia y tienen problemas para hacer frente a deudas contraídas, como luego detallaremos.

Nada sabemos de la época y las circunstancias en que murió Pero Guillén. En 1475, fecha en que escribe La gaya ciencia, se pierde su pista. Precisamente es su hijo Diego el primero en dar noticias de Pero Guillén. Escribe desde Roma en 1483, a petición de Alonso Carrillo, sobrino del arzobispo del mismo

${ }^{18}$ Para una visión general de las banderías que padeció Castilla en tiempos del valido, véase César Silió, Don Álvaro de Luna y su tiempo, Madrid, Espasa-Calpe, 1957.

19 José Amador de los Ríos, op. cit., pág. 221.

${ }^{20}$ Mirando mi mengua se doblan mis penas / En tal grado vivo que es muerta mi vida, / Veo a mis hijos por casas ajenas, / Mi honra y mi fama del todo perdidas: Carlos Moreno Hernández, op. cit., pág. 298.

${ }^{21} \mathrm{El}$ poeta se hace cargo de las tres principales culpas que se achacaban al Maestre: crueza, tiranía y usurpar la señoría del rey, y procura contestar a ellas. Acaba su dezir con valentía: Yo no sé por quáles modos / se encendió aquesta brasa:/ Justicia queremos todos / Pero non por nuestra casa: Carlos Moreno Hernández, op. cit., pág. 199.

22 Carlos Moreno Hernández, op. cit., pág. 290. 
nombre y obispo de Pamplona, un Loor del Reverendo señor don Alonso Carrillo en el que se refiere al gran amor que su padre, ya fallecido, sentía por el arzobispo. En esta obra, Diego Guillén dice ser canónigo de Palencia y familiar del cardenal Ursino. Amador de los Ríos señala que Diego Guillén obtuvo una canonjía en Palencia, aunque no le consta si llegó a ocuparla ${ }^{23}$. Podemos afirmar que sí lo hizo, pues distintos documentos de las Actas Capitulares de esa ciudad así lo indican. Años más tarde, en 1487, dedica también en Roma la traducción del Libro de la potencia y sapiencia de Dios de Hermes Trismegisto a Gómez Manrique. La relación de Diego Guillén con ambos personajes procede sin duda del tiempo que su padre pasó en la corte de don Alonso. Al arzobispo lo conoció bien y le demostró post mortem su agradecimiento al escribirle el Loor mentado. Esto dice mucho de la lealtad de los Guillén. Pero Guillén se atrevió a defender a don Álvaro de Luna cuando la causa del valido estaba ya perdida, y su hijo Diego hizo lo mismo con el arzobispo Carrillo después de haber caído este en desgracia, tras su ruptura definitiva con los Reyes Católicos en 1475.

Una parte importante de la vida de Diego Guillén transcurrió en Roma, donde dio cima a varias de sus obras. Desde esta ciudad escribe cartas en 1483, 1487, 1499 y 1500. Pero durante estos años viajó a Palencia en varias ocasiones. El 8 de junio de 1493 renuncia en esta ciudad a la canonjía de que disfrutaba (Actas Capitulares, fol. 8r), y el 10 de junio del mismo año le es concedido un préstamo (fol. 9r). El 10 de julio, un mes después de lo anterior, la canonjía que había dejado Diego Guillén va a parar a Pedro Guillén, clérigo de Ávila, a quien suponemos pariente de Diego, quizás hermano, por coincidencia del apellido y la ciudad, y por obtener préstamos conjuntos. El 5 de marzo de 1506, trece años después, leemos en las mismas Actas (fols. 134v-135r) que Diego Guillén recupera de nuevo su dignidad de canónigo de la catedral, y que permuta los beneficios de ella derivados por la cancelación del préstamo que arriba mencionamos. Hasta este año y desde 1493, no hay ningún documento en el archivo de la catedral de Palencia relativo a Diego Guillén, pero sí algunos sobre su hermano o pariente, Pedro Guillén de Ávila, que sufre varias sanciones por amancebamiento. Otro documento fechado el 7 de julio de 1507 (fol. 166r) menciona juntos a Diego y Pedro Guillén, racionero de la catedral. Se trata otra vez de un reconocimiento de deuda por el que se obliga a ambos a pagar 3.500 maravedíes a unos obreros, so pena de que les pongan a ambos un punto, es decir, se señale con un punto sus nombres, públicamente, entre los miembros del cabildo. Acordaron pagarla juntos en dos años y a plazos. No aparece Diego Guillén en la lista de canónigos de la catedral de este año, pero sí en las que van desde 1508 a 1510, fecha en que se pierde su pista.

${ }^{23}$ José Amador de los Ríos, op. cit., pág. 274. 
Existe la posibilidad de que la familia Guillén fuese conversa. No hay prueba documental alguna que avale esta hipótesis, aunque Moreno Hernández justifica de diversos modos sus sospechas. Primeramente, considera el importante papel jugado por los conversos en el entorno del arzobispo Carrillo. Rodrigo Cota, Juan de Mazuela, Antón de Montoro y Juan de Valladolid estuvieron relacionados de diversos modos con la casa de don Alonso. En segundo lugar, habría que tener en cuenta el oficio de contador que ejerció Pero Guillén al servicio de Carrillo. Hay además una alusión interesante de Pero Guillén en una carta de hacia 1467 demandando consejo a un su amigo sobre su vida en que dice: cuando por industria me levante del suelo donde ya los menudos del pueblo me refollaban, poniendome a las lanzas de todos ${ }^{24}$. La expresión los menudos del pueblo alude al vulgo cristiano viejo (pecheros, menudos o vulgares), origen principal de la persecución contra judíos y conversos ${ }^{25}$. Con esto no salimos del terreno de la conjetura. Los versos que Diego Guillén dedica a la expulsión de los judíos en el Panegírico a la reina Isabel, a pesar de su dureza, tampoco son una prueba. En parecidos términos se expresan otros conversos, muy interesados en curarse en salud ante cualquier duda ${ }^{26}$ :

\section{Y luego me dixo: la turba llorosa que ves con congoxa, mezquina y dispersa es la iudayca nación muy perversa, incrédula, dura, rebelde, engañosa (fol. 16r).}

Esta copla se encuentra al final del Panegírico que Diego Guillén escribió a la reina Isabel. El Panegirico a la Reyna doña Isabel... E otra obra en loor del reverendo señor don Alonso Carrillo, arçobispo de Toledo se imprimieron juntos en Valladolid en casa de Diego de Gumiel, en 1509, en 26 folios a dos columnas. Está en la Biblioteca Nacional con la signatura R-11-229 y con exlibris de Gayangos ${ }^{27}$. De esta edición hizo una edición facsímil la Real Acade-

${ }^{24}$ Carlos Moreno Hernández, op. cit., págs. 15-16.

25 Américo Castro, Aspectos del vivir hispánico, Madrid, Alianza Editorial, 1970, págs. $97-$ 103 y La realidad histórica de España, México, Porrúa, 1975, pág. 82. Francisco Márquez Villanueva, «The converso problem: An assessment» en Collected Studies in honour Américo Castro's 80th year, Oxford, Lincombe Lodge Research Library, 1965, págs. 318-319.

${ }^{26}$ Alonso de Santa Cruz, otro converso, habla de los judíos con dureza semejante: $Y$ doquier que ellos sabían que avía dineros, con todas sus astucias y mañas los procuraban de sacar... con engaños y asechanças y pleitos. Goçávanse con las tristeças de los cristianos... Finalmente heran la destrucción de ellos (Juan de Mata Carriazo, ed., Crónica de los Reyes Católicos de Alonso de Santa Cruz, Sevilla, CSIC, 1951, págs. 60-66).

${ }^{27}$ El incipit es el siguiente: Panegirico compuesto por Diego Guillen de Avila en alabança dela mas cathólica princesa y mas gloriosa reyna de todas las reynas, la Reyna doña Isabel, nuestra señora que santa gloria aya $\tau$ a su alteza dirigida. E otra obra compuesta por el mismo Diego Guillen en loor del reuerendissimo señor don Alonso Carrillo, arçobispo de Toledo que aya santa gloria. Explicit: Feneció esta obra en Roma por Diego Guillén de Avila a xxiii de 
mia en 1951 con motivo del 500 aniversario del nacimiento de Isabel. Tras el incipit, puede leerse:

Letra de Diego Guillén de Ávila, canonigo de Palencia a la reyna doña Isabel nuestra señora que aya gloria con una obra trobada que en su servicio compuso, la qual nunca vio, avn que le fue presentada, por sus ocupaciones y dolencias (fol. 2r).

En esta carta dedica su loor a la reina y le ruega que lo lea, y si sus muchas ocupaciones no se lo permiten, que al menos lo dé a conocer a otras personas duchas en humanidades para que no caiga en olvido. Y finalmente acaba la carta en Roma a xxvii de abril de quinientos. El Panegírico a la reina Isabel la Católica fue acabado por Diego Guillén en Roma el 23 de julio de 1499, según él mismo explica en la mentada carta. Palau y Dulcet supone la existencia de una primera edición de hacia 1500 en Roma, aunque reconoce no haber visto ejemplar ${ }^{28}$. Norton menciona una edición en Salamanca en 1507, pero no he hallado rastro de ella ${ }^{29}$. En total son 175 coplas, dispuestas a dos columnas de 5 coplas cada una en casi todas las páginas. Los elogios que se dedicaron a la reina son numerosísimos, aunque no conocemos otro Panegírico completo como el de Guillén. Sin embargo, cobró auge un género de historiografía en verso que, iniciado por Diego Guillén de Ávila, Alonso de Córdoba o Juan de Padilla, tuvo una de sus cumbres en la Consolatoria de Castilla (1484) de Juan de Barba (1429-1489), extensa exaltación mesiánica de los Reyes Católicos en arte mayor. Gómez Manrique, quizás la influencia más visible en Diego Guillén junto con su padre, escribió también versos en alabanza de Isabel al final de su Regimiento de príncipes, poema alegórico que ofreció a Isabel y su esposo cuando todavía no eran reyes. Estas alabanzas, escritas a la reina en vida, fueron seguidas de otras a su muerte, como la que puede leerse en la crónica de Andrés Bernáldez, cura de los Palacios. El cura dedica un capítulo completo a ensalzar las virtudes de la reina, que para él es un ser elegido y favorecido por Dios ${ }^{30}$. En la misma línea, Íñigo de Mendoza en su Dechado del regimien-

julio de año de noventa $\tau$ nueve, intitulola Panegirico que quiere dezir toda gloria o alabança, es vocablo griego impuesto por algunos latinos a sus obras, donde han loado emperadores, reyes $\tau$ grandes principes.

28 Antonio Palau y Dulcet, op. cit., pág. 581.

${ }^{29}$ Frederick J. Norton, La imprenta en España (1501-1520), Madrid, Ollero y Ramos, 1966, pág. 131.

30 ¿Quién podría contar las excelencias desta cristianísima y bien aventurada reina, muy digna de loa por sienpre? Allende de ella ser castiza y de tan noblísima y exçelentísima progenie de mugeres reinas de España, como por las corónicas se manifiesta, tuvo ella otras muchas excelencias de que Nuestro Señor la adornó, en que exçedió e traspasó a no digo tan solamente en España mas en todo el mundo, de aquellas por quien por sus virtudes o por sus gracias, o por su saber o poder, su memoria e fama vive, segund vemos por escripturas; y muchas de aquellas por sola una cosa que tuvieron o fizieron, vive y vivirá su memoria; pues quanto más 
to de príncipes compara a Isabel con la Virgen María ${ }^{31}$. Estas hipérboles no son infrecuentes. Antón de Montoro en su encendido elogio a Isabel raya en la blasfemia ${ }^{32}$.

El Panegírico se compone claramente de cuatro partes. En tres de ellas el poeta es guiado por una de las Parcas y dialoga con ella:

1) Comienzo: exordio, invocación, descripción del bosque mágico y de la mansión de las Parcas.

2) El pasado lejano: discurso de Atropos sobre la genealogía de la reina Isabel que incluye los citas y su mito, los reyes godos y los reyes de Castilla desde la destruyción de España por culpa de los pecados de don Rodrigo hasta Enrique IV.

3) El tiempo presente o pasado inmediato: discurso de Cloto que trata sobre el nacimiento de Isabel y sus virtudes, la boda con Fernando, la guerra con Portugal y la conquista de Granada.

4) El presente inmediato y el futuro: discurso de Lachesis sobre la expulsión de los judíos, la boda y muerte del príncipe Juan y pronóstico de grandes glorias futuras para la reina y Castilla.

Tras la toma de Alhama, Guillén deja de trabajar en el Panegírico durante un tiempo que no precisa, pero que podemos estimar en más de diez años: $E l$ autor prosigue esta obra mucho tiempo después que la començó; muda la consonancia de los quatro versos primeros y finge aver dormido el tiempo que no trabajó en ella (fol. 11v). La visita del rey Fernando a Alhama nos ayuda a datar esta interrupción después de agosto de 1482:

Aquí me traspuse gran pieça embevido, tras las esperanzas quel mundo me muestra, mas viendo mis piensas mi sabia maestra, despierta, me dixo, que mucho as dormido (fol. 11v)

\footnotetext{
de vivir la memoria y fama de reina tan cristianísima, que tantas excelencias tuvo y tantas maravillas Nuestro Señor, reinando ella en sus reinos, por ella obró e fizo: Manuel Gómez Moreno y Juan de Mata Carriazo, eds., Memorias del reinado de los Reyes Católicos de Andrés Bernáldez, Madrid, CSIC, 1962, págs. 485-488.

${ }^{31}$ Marcelino Menéndez Pelayo, ed., Antología de poetas líricos castellanos, 10 vols., Santander, CSIC, 1944, IV, pág. 379.

${ }^{32}$ Si no pariera Sant'Ana / hasta ser nascida vos, / de vos el Hijo de Dios / rescibiera carne humana. Estos versos son remedo de un villancico contenido en el Cancionero de Upsala y, como le recordó al autor el portugués Álvaro de Brito, le hubieran llevado a la hoguera en otra tierra (Francisco Cantera Burgos y Carlos Carrete Redondo, eds., Cancionero de Antón de Montoro, Madrid, Editora Nacional, 1984, págs. 30-31). También se escribieron elogios a la reina fuera de España, como por ejemplo, el que le dedicó Baltasar de Castiglione (Rogelio Reyes Cano, ed., El Cortesano de Baltasar de Castiglione, Madrid, Espasa-Calpe, 1984, pág. 34).
} 
Cuando recupera el hilo del poema, Guillén cuenta la guerra de Granada y la expulsión de los judíos. Menciona también, ya al final, la muerte del príncipe Juan acaecida el 4 de octubre de 1497. Sorprendentemente no dice nada del descubrimiento de América. Es evidente que la última parte del Panegírico se escribió apresuradamente y de manera un tanto desordenada. ¿Por qué interrumpe Diego Guillén la redacción de su obra? Repárese en que el canónigo envía el elogio del arzobispo a su sobrino en diciembre de 1483 y que el de la reina se detiene después de agosto de 1482. Parece que fue escribiendo ambos a la vez y que acabó para esas fechas el uno, y el otro lo dejó en suspenso. Esto plantea varios interrogantes. Primeramente si Guillén escribió el Panegírico de Isabel para expresar inequívocamente su lealtad a la reina, de la que podía dudarse si componía un elogio al arzobispo que la traicionó. Los Guillén, como ya señalamos arriba, fueron notablemente leales a sus benefactores, incluso en la adversidad. Difícilmente hubiera podido Diego negarse a la petición del sobrino del arzobispo sin mostrarse desagradecido, pero quizás pensó que si escribía un elogio al arzobispo tenía que escribir otro a la reina, en compensación. Puede que un Panegírico provocara el otro. No parece, sin embargo, que doña Isabel se dejara impresionar por él, puesto que nunca lo leyó. En última instancia desconocemos las causas concretas que provocaron la interrupción, aunque no es pequeño motivo el manifiesto desinterés de la soberana. La parte última es evidente que se acabó a toda prisa, y su final descuidado contrasta con la meticulosa planificación de la parte escrita antes. El poeta termina elogiando nuevamente a la reina y pidiendo disculpas por su torpeza:

Princesa y señora, o reyna, tu alteza, visto que vengo de tierras tan luengas, perdone mis faltas, perdone mis menguas, perdone mi simple y tosca rudeza. Si no trayo toda tu antigua nobleza, tus grandes virtudes, tus glorias escritas, tus obras lo causan que son infinitas.

No ay libro do quepan según su grandeza. Laus deo. (fol. 17r)

En el mismo volumen ${ }^{33}$, y tras el explicit del Panegírico a la reina Isabel, leemos: Siguense unas coplas que hizo el muy reverendo señor don Alonso Carrillo, obispo de Pamplona a Diego Guillén de Ávila, rogandole que haga alguna obra en memoria del reuerendissimo señor don Alonso Carrillo, arçobispo de Toledo, su tío. En ellas el sobrino de don Alonso Carrillo explica las causas que lo mueven a pedirle a Diego que escriba tal elogio, y la principal es el olvido en que han caído las acciones dignas de ser recordadas de su tío. No

${ }^{33}$ R-11-26 de la Biblioteca Nacional de Madrid. 
menciona los Hechos de don Alonso Carrillo, escritos por el padre de Diego, obra que parece desconocer:

Pues vos, como hijo de tan buen criado, onrrado y querido daquel mi señor, quen vida le fue contador mayor rigie y gouernaua su honrra y estado.

Si él se hallara al fin ultimado daqueste perlado y gran caballero, sé bien que hiziera sin ser lisongero de sus grandes hechos un luengo tratado. Razón es que tome su mesmo sabor el fruto que al árbol tan bueno nos dexa. Virtud y crianza razón os aquexa que pongáys las manos en esta labor. Sus actos famosos os dan tal clamor que al sordo despiertan que oya que diga a vos que digáys razón os obliga, y a mí porque sea solicitador. (fol. 20r)

Tras el incipit $^{34}$ puede leerse la carta escrita por Diego Guillén al obispo de Pamplona. En ella se excusa por su tardanza, causada por los pocos espacios que en esta corte tenemos los que como yo voluntades agenas seguimos, y afirma:

me metí en este laberinto mouido por le seruir $\tau$ incitado del amor $\tau$ antigua aficion que al dicho señor siempre tuue, así por el tiempo que mi padre, que Dios aya, fue en su casa como por que sus magnificencias fueron tales que no solo a los que las sentimos mas a quantos las oyeron aficionaron.

Y firma la carta en Roma a 20 de diciembre de 1483.

Diego Guillén está a la sazón en esta ciudad al servicio del cardenal Ursino. Del contenido de la carta se deduce que lleva allí bastante tiempo. Si el Proemio a La gaya ciencia con los hechos guerreros notables del arzobispo Carrillo fue escrito en 1474, y fue la última obra de Pero Guillén, este evidentemente murió entre 1474 y 1483, ya cumplidos los 70 años. Afirma Moreno Hernández que tanto el Panegírico de Carrillo como el de la Reina Católica fueron composiciones escritas a petición del sobrino de Carrillo ${ }^{35}$, pero no hay dato alguno que permita suponer que el loor dirigido a la reina se debiera a una petición del sobrino del arzobispo de Toledo.

${ }^{34}$ El incipit del loor al arzobispo es el siguiente: Obra compuesta por Diego Guillén de Ávila, canonigo de Palencia, familiar del reverendíssimo señor cardenal Ursino, en loor del reuerendissimo señor don Alonso Carrillo arzobispo de Toledo que aya santa gloria, por mandado del muy reverendo $\tau$ magnifico señor don Alonso Carrillo, obispo de Pamplona, su sobrino e a su señoria dirigida (fol. 21r).

${ }^{35}$ Carlos Moreno Hernández, op. cit., pág. 17. 
Ambos Panegíricos están escritos siguiendo la moda dantesca, tentación a la que sucumbieron no pocos poetas del siglo XV. Tras la muerte en 1458 del Marqués de Santillana, don Diego Gómez Manrique compuso El planto de las virtudes y poesía, poema alegórico-dantesco dedicado al triste deceso y dirigido a su hijo, el obispo de Calahorra, don Pedro González de Mendoza, el futuro cardenal y arzobispo de Toledo. En él imita La coronación de Mosén Jordí de Sant Jordí y La comedieta de Ponza, del propio don Ínigo. Traza aquí don Gómez una de esas visiones poéticas cuatrocentistas, en la cual, tras la invocación, describe el tiempo de la muerte, el día, el paisaje y un castillo al que llega de mañana, penetrando en unas salas donde las siete virtudes loan al magnífico marqués, así como a ilustres literatos y personajes. El comienzo de los dos panegíricos de Guillén es semejante al de Manrique. En ambos casos hay una descripción de tiempo y paisaje, con referencia a los astros. En el Panegírico isabelino sigue la llegada del poeta a una mansión fabulosa cuyas salas va recorriendo, como Gómez Manrique en su visión. En el caso de Guillén es la mansión de las Parcas, en cuyos muros está escrita la historia de Isabel y de Castilla. El recorrido por las siete virtudes, en cambio, no está en este Panegírico sino en el que Guillén compuso en alabanza de Alonso Carrillo.

En su elogio a don Íñigo, Gómez Manrique procura seguir los pasos del Marqués, el cual había hecho lo propio con don Enrique de Villena cuando escribió la Defunsión de don Enrique de Villena ${ }^{36}$. El Marqués se fijó en los Doze trabajos de Hércules, y don Gómez a su vez reproduce la forma alegórica de la Defunsión. Para la descripción del valle halla su fuente en la Comedieta de Ponza ${ }^{37}$ y también en la Coronación del Marqués de Santillana de Juan de $\mathrm{Mena}^{38}$, aunque la repetición de lugares comunes es tan frecuente en los textos alegóricos que es difícil precisar los vínculos. Todos estos valles sobrenaturales, los de Mena, Santillana, Manrique y Diego Guillén, son muy parecidos. Hallamos, sin embargo, alguna semejanza de planteamiento (tres damas como guías y un valle sobrecogedor) entre el Panegírico a Isabel y la Visión de amor de Santillana. Aquí el Marqués presenta a tres damas, en este caso las Virtudes, que se han retirado a un valle espantoso, pues en España no hallan lugar donde asentarse ${ }^{39}$.

La alegoría dantesca tuvo bastante predicamento entre los autores vinculados a Alonso Carrillo. Gómez Manrique escribió una continuación de las Co-

36 Joaquín G. Casalduero, «La Defunsión de don Enrique de Villena del Marqués de Santillana» en Estructura y diseño en la literatura castellana medieval, Madrid, Porrúa, 1975, págs. 180-185.

37 Ángel Gómez Moreno y Maximilian P. A. M. Kerkhof, eds., Obras completas del Marqués de Santillana, Barcelona, Planeta, 1988, págs. 163-209.

38 Rafael Lapesa, La obra literaria del Marqués de Santillana, Madrid, Ínsula, 1957, pág. 296.

39 Ángel Gómez Moreno y Maximilian P. A. M. Kerkhof, op. cit., pág. 111. 
plas contra los pecados mortales de Juan de Mena. Además, tanto él como Pero Guillén se propusieron terminar Las Trescientas, la obra magna del cordobés ${ }^{40}$. La moda estaba, sin embargo, muy extendida. García de Pedraza, Francisco Imperial, Juan de Padilla y otros siguieron la corriente dantesca ${ }^{41}$. Pero Guillén había también escrito una composición, Dezir sobre Amor, fecho en Vall de Parayso, siguiendo el estilo al uso. Pero es la Obra compuesta y ordenada por Pedro Guillén de Sebilla contador del muy magnífico señor D. Alonso Carrillo, dirigida y diferida a su señoría ${ }^{42}$ la que con diferencia más se asemeja a los Panegíricos dantescos del hijo. La obra del padre es un recorrido alegórico a través de un edificio maravilloso donde moran las siete artes personificadas, como en el caso de Gómez Manrique. El paseo dantesco de los dos poetas es muy semejante. Recordemos que ambos fueron amigos. A cada arte le corresponden un planeta y siete círculos. En cada uno de ellos, al final del recorrido, y tras la descripción de virtudes y nombres dignos de recordación, aparecen los príncipes Isabel y Fernando junto al arzobispo. El espíritu mesiánico que asoma a menudo en la poesía de esta época aflora aquí y vemos a los futuros reyes, designados por Dios para altísimas empresas, conducidos a sus altos destinos por la mano providencial de don Alonso ${ }^{43}$. Los tiempos de la ruptura están todavía lejanos. La descripción del palacio maravilloso semeja la casa de las Parcas del Panegírico a la reina Isabel, mientras que los elogios dedicados por Diego a Carrillo en el recorrido por las virtudes de la mano de Dante semejan grandemente los que su padre había dirigido a su benefactor. No obstante, y esto es una diferencia importante, Diego es cuidadoso y se guarda muy bien de mezclar a los reyes con el arzobispo. La ruptura entre Carrillo y los reyes había sido abrupta y no convenía recordar los tiempos de estrechísima amistad entre el prelado y los príncipes, o los beneficios que estos habían recibido de aquel. Este es precisamente el aspecto más destacado por el padre en su elogio a Carrillo, pero los tiempos han cambiado. En el Panegírico a Isabel, Diego Guillén apenas alude a don Alonso una vez y de pasada, sin decir su nombre siquiera ${ }^{44}$. Y en el Panegírico de Carrillo, evita toda referencia a los monarcas o a cualquier circunstancia o hecho relacionado con el divorcio espectacular que protagonizaron los reyes y quien había sido su más firme valedor en los tiempos difíciles.

${ }^{40}$ Francisco Vidal González, ed., Cancionero de Gómez Manrique, Madrid, Cátedra, 2003, pág. 55.

${ }^{41}$ Francisca Vendrell de Millás, Cancionero de Palacio, Barcelona, CSIC, 1945, págs. 133-136.

42 Carlos Moreno Hernández, op. cit., págs. 345-401.

${ }^{43}$ Eloy Benito Ruano, op. cit., págs. 112-134.

${ }^{44}$ Diego trata muy por encima del matrimonio de Isabel y Fernando, porque lo había celebrado y hecho posible Carrillo, nombrado en el texto como el claro primado sin más precisiones: Allí pues venidos con bultos hufanos / lucientes antorchas la noche vencían, / el claro primado les junta las manos / con las cerimonias que se requerían. (fol. 9r) 
A Diego Guillén se atribuye además una pieza teatral. La Égloga interlocutoria fue impresa en Alcalá de Henares por Estanislao Polono hacia 1511. Identificar a Diego de Ávila, autor teatral, con Diego Guillén de Ávila, autor de los Panegíricos a la reina Isabel y a don Alonso Carrillo, no puede hacerse sin asomo de duda. E. Kohler, el primer editor moderno del texto, se limita a apuntar la posibilidad de que se trate de la misma persona ${ }^{45}$. Alfredo Hermenegildo en una edición mucho más reciente no va más lejos ${ }^{46}$. Del texto en sí se deducen algunos datos concretos que podemos resumir así:

1) que la Égloga está dedicada al Gran Capitán, a quien uno de los personajes, Alonso Benito, llama nuestro amo,

2) que todos los personajes se declaran cortesanos de don Pedro de Acuña y se dice que en su palacio vivirá por expreso deseo divino el Gran Capitán hasta que conquiste Jerusalén,

3) que don Pedro de Acuña es amigo íntimo de don Gonzalo Fernández de Córdoba.

La dedicatoria a don Gonzalo y el comentario del personaje Alonso Benito indujeron a James Crawford a afirmar que el autor pertenecía al círculo del Gran Capitán y que la Égloga, que es una típica farsa de bodas, debió escribirse para ser representada en 1509 como parte de los festejos que rodearon la boda de Elvira, la hija única de don Gonzalo, con el Condestable de Castilla, don Bernardino de Velasco ${ }^{47}$. Este particular viene a reforzar la posibilidad de que Diego Guillén sea el autor de la Égloga, pues por estos años tradujo los Stratagemata de Frontino para don Pedro Fernández de Velasco, conde de Haro, lo que prueba que tenía relación con la ilustre familia de los condestables. Diego romancea el texto de Frontino para el padre del novio y consuegro del Gran Capitán, y afirma que su traducción es una consecuencia de su propósito de servir a Vuestra ilustre Señoría con los trabajos de mis vigilias e estudio (Biblioteca Nacional, R-31.603, fol. 2r). Dice trabajos, de manera que bien pudo escribir otros para don Pedro, entre ellos esta farsa de bodas para el casamiento de su hijo. Las fechas se compadecen bien, ya que la boda se celebró en 1509, y la obra fue compuesta antes de 1511, fecha en que Hernando Colón compró un ejemplar para su biblioteca ${ }^{48}$. Recordemos además que desde 1508

${ }^{45}$ Eugen Kohler, ed., Sieben Spanische Dramatische Eklogen, Dresden, M. Niemeyer, 1911, págs. 236-266.

${ }^{46}$ Alfredo Hermenegildo, ed., Teatro renacentista: Juan del Encina, Diego de Ávila, Madrid, Espasa-Calpe, 1990, pág. 66.

47 James P. Crawford, Spanish Drama before Lope de Vega, Philadelphia, University of Philadelphia Press, 1937, pág. 77.

${ }^{48}$ El ejemplar de Hernando Colón llevaba inscrito «costó en Alcalá de Henares 8 maravedis en $1511 »$. 
a 1510 Diego Guillén aparece en las listas de canónigos de la catedral de Palencia.

No puede considerarse de primer orden la obra literaria de Diego Guillén, pero tampoco merecedora del olvido. De su producción, sólo la pieza teatral, de atribución dudosa, ha recibido atención. Los dos Panegíricos siguen careciendo de una edición moderna. Su mérito literario no es sobresaliente, pero el Panegírico a la reina Isabel es un texto del mayor interés para ilustrar cómo fraguan los tópicos de la historia de Castilla y España en la época preimperial, precisamente en manos de muchos autores conversos. En cuanto al Panegírico de Carrillo interesa por lo mismo, y también porque proporciona datos importantes de la vida del arzobispo de Toledo, que fue un personaje crucial en la historia de Castilla, a pesar del olvido a que ha sido condenado.

Como traductor, Diego Guillén supera al poeta. La actividad traductora de Diego Guillén tiene como dedicatarios a personajes relacionados con su padre y con el arzobispo de Toledo. Dio cima a tres versiones de envergadura, de que nos ocuparemos a continuación.

La Historia de Herodiano se conserva en Yale en un manuscrito copiado en torno a 1500 (Yale, ms. 182, fols. 5r-112r) ${ }^{49}$. El romanceamiento que hace Diego se basa en la versión latina de Angelo Poliziano que se editó por primera vez en Bolonia en 1493, aunque Poliziano consultó y usó los manuscritos griegos de Herodiano que estaban en Florencia ${ }^{50}$. Ningún autor por mí consultado cita esta traducción de Herodiano como obra de Diego Guillén de Ávila ${ }^{51}$. Amador de los Ríos se refiere sólo a las traducciones de Frontino y de los textos herméticos e igualmente otros autores ${ }^{52}$.

La traducción de Diego Guillén de Ávila de los Stratagemata de Sexto Julio Frontino fue dada a la imprenta en 1516 en Salamanca por Liondedei (Biblioteca Nacional, R-31.603) ${ }^{53}$. El incipit es este:

${ }^{49}$ En la traducción contemporánea española de Juan J. Torres Esbarrach, ed., Historia del Imperio Romano de Herodiano, Madrid, Gredos, 1985, pág. 83, se señala que existe un gran vacío en cuanto a ediciones y traducciones de Herodiano es España, y se afirma que «únicamente contamos con una traducción... Es obra del protonotario Fernán Flores de Xerez y fue publicada en 1532». No nombra la traducción de Diego Guillén.

${ }^{50}$ G. Vitelli, «Codici fiorentini dello storico Erodiano», Studi italiani di filologia clasica, 2, 1894, pág. 470.

${ }^{51}$ Incipit: Síguise la epístola de Angelo Policiano al papa Ynocencio octabo et la traducción de la estoria de Erodiano del griego en latýn, la qual Diego Guillén de Ávila trasladó de latín en romance.

52 José Amador de los Ríos, op. cit., pág. 210; José Simón Díaz, Bibliografía de la literatura hispánica, Madrid, CSIC, 1965, pág. 156.

${ }^{53}$ Diego Guillén de Ávila, trad., Stratagemata de Sexto Julio Frontino, Valencia, Vicent García, 2002. Es facsímil de la edición de Salamanca de 1516. 
Los cuatro libros de Sexto Julio Frontino, Consul romano. De los enjemplos, consejos $\tau$ avisos de la guerra: obra provechosa, nuevamente trasladada del latín en nuestro romance castellano, e nuevamente impresa. Cum privilegio.

Repárese en las expresiones nuevamente trasladada y nuevamente impresa. La primera hace pensar que el editor conocía las traducciones anónimas de Frontino que ya existían, o al menos una de ellas, aunque Diego parece dar a entender que el texto de Frontino no tiene traducción al castellano anterior a la suya:

gocen $\tau$ se aprovechen en su mesma lengua castellana deste tan antiguo $\tau$ provechoso libro los Capitanes $\tau$ los otros hombres de guerra que no aprendieron la latina en cabo de tantos tiempos como ha que fue copilado, sin tener ellos noticia ninguna del (fol. 2r).

Más desconcertante es el comentario, nuevamente impresa, pues no hay indicios de que existiera otra impresión anterior, ni de la traducción de Diego Guillén ni de ninguna otra ${ }^{54}$. Afirma Palau y Dulcet que este romanceamiento es libro raro y estimado que ha figurado en la biblioteca del Marqués de Jerez y existe en el Museo Británico, pero no me consta ${ }^{55}$.

En el folio segundo se contiene la carta que Diego Guillén dirige a don Pedro de Velasco, conde de Haro, con interesante información sobre las circunstancias en que se hizo esta traducción. La carta está reproducida en el catálogo de Bartolomé Gallardo ${ }^{56}$. Este don Pedro de Velasco, condestable que fue de Castilla, es hijo de otro don Pedro Fernández de Velasco, llamado el Bueno, que fue el primer conde que llevó este título. Afirma Guillén que Después de que determiné conmigo de servir a Vuestra ilustre Señoría con los trabajos de mis vigilias $\tau$ estudio, me ha parescido de servirle en romanzar el libro o Estrategemáticon de Frontino. Este trabajo, sin embargo, tiene por objetivo no enseñar al conde, que ya es experto en estos menesteres y buen latinista, sino servir al bien público:

por servir a Vuestra Señoria $\tau$ aprovechar a nuestra castellana Republica tome el trabajo de romanzarle, conformandome con aquella sentencia de Aristotiles donde dice que se debe mas amar el bien publico que no el proprio. Asi yo pospuse la fatiga propria al provecho del bien publico, $\tau$ saque este libro del latin en el mas claro $\tau$ llano romance que pude.

La lectura de los clásicos es considerada provechosa por los hombres del siglo XV. Por eso, la traducción llega a ser considerada como un beneficio para

54 José Simón Díaz, op. cit., pág. 167 y Norton, op. cit., pág. 294.

55 Antonio Palau y Dulcet, op. cit., pág. 511.

${ }^{56}$ Esta traducción es la única obra que Gallardo atribuye a Diego Guillén: Bartolomé J. Gallardo, Ensayo de una biblioteca española de libros raros y curiosos, 4 vols., Madrid, Ed. Biblioteca Nacional, 1888, III, pág. 151. 
la nación. Esta idea, expresada por Diego Guillén, es compartida por otros traductores que hacen gala de los mismos elevados propósitos e idéntico orgullo por su trabajo. Así, el anónimo traductor que a mediados del siglo XV romancea la Política de Aristóteles escribe que por la mayor parte vemos que todos los hombres que rigen ciudades e repúblicas y cosas familiares no alcançan ser latinos, de donde muchas veces les falta la manera de governar, y por esta razón, ha decidido él traducir la obra, para que tuviessen preceptos con los quales supiessen regir y governar. El poeta y cortesano navarro Hugo de Urríes, en el prólogo a su traducción de Valerio Máximo realizada en 1467 e impresa con una dedicatoria a Fernando de Aragón en 1495, dice haber hecho singular beneficio a su patria. El mismo empeño, aprovechar mi tierra... ca poco aprovechan las armas si no andan acompañadas de consejo, expresa Diego López de Toledo, que tradujo a César, antes de participar en el sitio de Granada en $1492^{57}$. Insistiremos un poco más sobre esto. La labor de traducción es beneficiosa a la sociedad, pues sirve para poner a disposición de muchos lo que de otro modo estaría sólo al alcance de unos cuantos. Esta idea, ya frecuente en la última parte del siglo XV, alienta desde décadas antes, si bien no tan claramente expresada. Así Santillana, por ejemplo, aunque puede leer el Arbre de batailles de Honoré Bouvet en francés, pues conoce esta lengua, encarga a Antón Zorita que lo traduzca al castellano, para que pueda así ser leído no sólo por los de su casa, sino también por otras gentes del reino:

enpero todos los de vuestra noble casa, nin aun otros muchos deste rregno d'Esperia, por el lenguaje ser peregrino, non lo entienden, o a lo menos con mucho trabajo e dificultat vienen a la inteligençia de las materias en el dicho libro tractadas. Por lo qual vuestra merçed... me mandó que yo me trabajase en reduzirlo en lengua castellana ${ }^{58}$.

Hay en la Biblioteca Nacional de Madrid una traducción anónima de Frontino que se conserva en tres manuscritos, uno de los cuales, el 9253, ha sido erróneamente confundido con la traducción de Diego Guillén, según podemos ver en ARIADNA y BETA, y en el catálogo de Charles Faulhaber ${ }^{59}$. El error segu-

57 Th. S. Beardsley, Hispano-classical translations printed between 1482 and 1699: A study of the prologues and critical bibliography. Tesis doctoral. Universidad de Pennsylvania, 1961, citado por Jeremy Lawrance, «On fifteenth-century Spanish Vernacular Humanism», en Medieval and Renaissance Studies in honour of Robert Brian Tate, Oxford, Dolphin Books, 1986, págs. 72-73.

${ }^{58}$ Carlos Alvar y Ángel Gómez Moreno, «Traducciones francesas en el siglo XV: el caso del Árbol de batallas de Honoré Bouvet», en Fidus interpres. Actas de las I Jornadas Nacionales de Historia de la Traducción, León, Servicio de Publicaciones de la Universidad de León, 1987, pág. 34.

${ }^{59}$ Charles Faulhaber et alii, Bibliography of the old Spanish texts, Madison, Seminary of Medieval Studies, 1984, pág. 129. 
ramente se debe a que ya existía una traducción de Frontino en la casa de los Velasco ${ }^{60}$.

La última traducción de Diego Guillén es el Libro de la potencia y sapiencia de Dios de Hermes Trimegisto. Se trata de un romanceamiento de la versión latina que hizo Marsilio Ficino de la citada obra ${ }^{61}$. La atribución hecha por Viña Liste, según la cual el autor de esta traducción pudo ser Diego Guillén de Ávila, es correcta ${ }^{62}$. El trabajo está dedicado a Gómez Manrique en Carta enviada de Roma por Diego Guillén, familiar del reverendísimo señor Cardenal Ursino al muy noble caballero el señor Gómez Manrique. La epístola la escribe Diego Guillén desde Roma en 1487. En ella informa que acabó su traducción en febrero de ese año. La carta y los textos herméticos están en la biblioteca del Escorial (b. IIII. 29) y fueron copiados en $1491^{63}$. En el folio 38 comienza el manuscrito con la versión de Diego Guillén, sin hoja de separación, que ha sido claramente arrancada, aunque la numeración del margen superior derecho no lo refleje ${ }^{64}$. Zarco Cuevas en su catálogo sólo incluye tres líneas de la carta, por lo que nos ha parecido de interés reproducirla en toda su extensión.

${ }^{60}$ Se conservan en la Biblioteca Nacional de Madrid tres manuscritos con una misma traducción anónima de los Stratagemata de Frontino cuya edición preparamos. Son los códices 9608, 10204 y 9253. El códice 9608 perteneció a don Pedro Fernández de Velasco, llamado el Bueno, y padre de otro don Pedro Fernández de Velasco, también conde de Haro, para quien Diego traducirá otra vez a Frontino. Para no perder el hilo, por tanto, téngase presente que hay dos don Pedros, padre e hijo, y dos traducciones de Frontino. El manuscrito 9608 es muy probablemente el que fue donado por el primer conde, llamado el Bueno, a su Hospital de la Veracruz en Medina de Pomar y no el códice 9253, como afirma Jeremy Lawrance: op. cit., pág. 1103. Hemos llegado a esta conclusión por el siguiente motivo. Si consultamos el catálogo de la biblioteca del conde de Haro (Biblioteca Nacional, ms. res. 141) que contiene una copia dieciochesca del catálogo original, encontramos que en él se consigna, en el inventario de 1553, un libro que ya consta en el inventario de 1455 como asiento LII y del que se dice: Julio Frontino que trata de diversas mañas y exemplos para el Capitán... Y después trata por treinte y seis reglas de las batallas y al fin, escrive una carta de loas de los capitanes de la guerra, todo escrito de mano en Romance (fol.12v). Pues bien, esas 36 reglas aparecen tras Frontino en el manuscrito 9608 (fols. 63-77v) y constituyen un ejemplar no localizado hasta ahora del Libro de la Guerra que fue atribuido erróneamente a Enrique de Villena y que Lucas de Torre editó siguiendo otro manuscrito (Biblioteca Nacional, ms. 6526, fols. 61v-85v): «El Libro de la guerra», Revue Hispanique, 38, 1916, págs. 491-531. Creemos que este dato identifica inequívocamente el manuscrito 9608 como el perteneciente a don Pedro Fernández de Velasco, primer conde de Haro y gran amigo del Marqués de Santillana.

${ }^{61}$ Hermes Trimegisto, Liber de potestate et sapientia Dei. Corpus Hermeticum I-XIV. Versiones latina di Marsilio Ficino, Florencia, S.P.E.S, 1983. Es facsímil de la editio princeps de 1471.

62 José M. ${ }^{a}$ Viña Liste, op. cit., pág. 158.

63 Julián Zarco Cuevas, op. cit., págs. 64-66. Juan de Herrera llegó a poseer una copia de esta traducción: René Taylor, «Libros herméticos de Juan de Herrera y Felipe II» en Arquitectura y magia. Consideraciones sobre la idea de El Escorial, Madrid, Siruela, 1995, págs. 137-141.

${ }^{64}$ Incipit: Argumento de Marssillio Ficino florentín en el libro de Mercurio Trismegisto trasladado del latín en romançe por Diego Guillén, familiar del reverendíssimo señor cardenal Ur- 
Traslado de una carta enviada de Roma por Diego Guillen, familiar del reverendíssimo señor Cardenal Urssino, al muy noble cavallero el señor Gomez Manrique, corregidor de la cibdat de Toledo, con una obra de un tratado del libro de Mercurio Trismegisto, trasladado de latin en romançe por el dicho Diego Guillen $\tau$ la carta dize assy:

Noble y muy virtuoso señor:

Commo por diversos respectos a vuestra señoria sea mucho obligado, y asta agora el deseo que de servir le tengo, con ocupaçiones non aya puesto en obra, commo quier que aun non libre de aquellas, pensse de traduzir alguna obra de latin en nuestro romançe $\tau$ dedicar la so el nombre de vuestra merçed, assy por lo suso dicho como por que la tal obra, por el tal nombre, perdurable mente viviesse $\tau$ conociendo la voluntad que a las scripturas antiguas tiene, pensando con qual antes seruir le podria, ocurrio me un tratado de Mercurio Trismigisto, de la potençia y sapiençia de Dios. E este pues delibre de romançar por ser en parte catholico, sy dezir se puede seyendo por hombre gentil y tan antiguo compuesto. E por que en el prologo de Marsillo van declaradas la uida de Mercurio y continencia deste tratado, non digo mas sinon que por el vea vuestra merçed el error que comun mente se tiene creyendo que a los gentiles non proveniesse el cognosçimiento de un Dios fazedor $\tau$ governador de todas las cosas, Nuestro Señor. La noble persona y estado de vuestra merced prospere. De Rroma a çinco de abrill de ochenta $\tau$ siete años, que las manos de vuestra merced vesa, Diego Guillén.

En conclusión, la obra de Diego Guillén como traductor es tanto o más importante que su trabajo de creación literaria. Vertió del latín al castellano la Historia de Herodiano, el Stratagematon de Frontino y el Libro de la potencia y sapiencia de Dios de Hermes Trimegisto. Frontino lo tradujo para el conde de Haro y los escritos herméticos para Gómez Manrique, de manera que al menos dos de sus traducciones se hicieron para nobles que se interesaban por la cultura. Los nobles castellanos en el siglo XV, y aun antes, compiten no sólo por tierras y poder, sino que también aspiran a una distinción cultural que engendró formas diversas de mecenazgo, formación de bibliotecas y encargo de traducciones ${ }^{65}$. Hemos dicho más arriba que traducir llegó a ser considerado como una actividad beneficiosa para el país, y muchos traductores se muestran orgullosos de rendir este servicio, entre ellos Diego Guillén. Esto se debe en gran parte a que el Cuatrocientos castellano ve los clásicos de un modo ejem-

sino. Explicit: Fenece el libro de Mercurio Trismegisto trasladado de griego en latín por Marsillo Facino florentín en el año de mill $\tau$ quatro cientos $\tau$ sessenta $\tau$ tres años en el mes de abrill. E del latín vuelto en el romançe castellano por Diego Guillén familiar del reverendíssimo señor cardenal Urssino en el año de mill $\tau$ quatro cientos $\tau$ ochenta $\tau$ cinco años en el mes de hebrero. Del qual dicho traslado original saqué este otro traslado, yo, Juan de Segura, capellán del señor Pero Nuñez de $T^{o}$, mi señor, en el año de mill $\tau$ quatro cientos $\tau$ noventa y uno en el mes de noviembre.

65 José Francisco Ruiz Casanova, Aproximación a una historia de la traducción en España, Madrid, Cátedra, 2000, pág. 91. 
plar. Es un nuevo didactismo que conjuga lo cristiano con las historias, legendarias o reales, del mundo antiguo. Las fuentes grecolatinas son un modelo.

Es cierto que el humanismo en su vertiente filológica no triunfa en España hasta Nebrija, y que hasta finales del siglo XV el conocimiento del latín es muy escaso en la península ${ }^{66}$, pero esto no implica que el interés por los clásicos, al menos desde la generación de Santillana e incluso antes, sea tibio. Señala Peter E. Russell que, si se quiere entender bien el humanismo del siglo XV en Castilla, debe diferenciarse marcadamente de su coetáneo italiano, porque no fue un «humanismo clásico» en el sentido que le dieron los vecinos, sino más bien un humanismo clasicista que pretendía ensanchar y revitalizar la cultura clásica sin despegarla por completo de lo medieval ${ }^{67}$. Nosotros añadiríamos que uno de los rasgos peculiares del humanismo español es una fusión originalísima de amor a los clásicos y pervivencia de lo medieval-caballeresco, que está muy lejos todavía de haber sido bien estudiada, y cuya exposición aquí nos alejaría mucho del concreto propósito de este artículo ${ }^{68}$. De manera que nos limitaremos a señalar que la conjunción de estas dos circunstancias, a saber, una nobleza interesada por los clásicos y la cultura, pero en gran parte desconocedora del latín, provocará una época dorada de la traducción en España que dejará huellas perdurables e intensas en el idioma ${ }^{69}$.

La vida intelectual de Diego Guillén aparece ligada a la de su padre de distintos modos, y es en parte consecuencia de los vínculos personales y políticos de Pero Guillén en el círculo de Alonso Carrillo. Primeramente escribe dos Panegíricos, uno dedicado al arzobispo y otro a la reina Isabel, que bien pueden considerarse conciliatorios. Sabido es que Carrillo, que apoyó en un primer momento a Isabel y Fernando, se enfrentó a ellos después. Las desavenencias entre Carrillo y los príncipes empiezan poco después de la boda, que Carrillo había hecho posible y hasta celebrado, y pasa por distintos avatares hasta la ruptura total en $1475^{70}$. Aquí Gómez Manrique, capitán de su mesnada, se desliga del arzobispo de Toledo y permanece leal a los reyes. Cuando la

${ }^{66}$ Para un panorama general de la situación del latín en la Castilla prerrenacentista, véase Francisco Rico, Nebrija frente a los bárbaros, Salamanca, Servicio de Publicaciones de la Universidad de Salamanca, 1978. Rico aplica aquí un concepto muy restringido, casi filológico, del Humanismo. Desde este punto de vista el Humanismo apenas si existe en Castilla hasta muy tarde.

${ }^{67}$ Peter E. Russell, Traducciones y traductores en la Península Ibérica (1400-1550), Barcelona, Servicio de Publicaciones de la Universidad Autónoma, 1984, pág. 229.

${ }^{68}$ Sobre esto publicaremos en breve el libro Clasicismo y caballería en el Cuatrocientos castellano. Edición de la traducción de Frontino que perteneció al Conde de Haro (en prensa).

${ }^{69}$ Rafael Lapesa, Historia de la lengua española, Madrid, Gredos, 1981, págs. 265-290.

${ }^{70}$ Para una visión general, aunque poco favorable al arzobispo, de la relación entre Isabel y don Alonso, véase Tarsicio de Azcona, Isabel la Católica, Madrid, Ed. Católica, 1964, pág. 200 y ss., y también Albert J. Sicroff, Les controverses des statuts de pureté de sang en Espagne de XVème siècle, Paris, Didier, 1960, págs. 95-98, 106-108, 126 y 150. 
guerra civil acaba, Carrillo es sometido y recluido en su casa de Alcalá. Podemos preguntarnos qué movió a Diego Guillén a escribir elogios conjuntos a personalidades tan enfrentadas y qué llevó al sobrino del belicoso arzobispo a solicitar un Panegírico de su tío, precisamente, al hijo de Pero Guillén. El motivo último puede muy bien haber sido echar tierra sobre las disputas entre el arzobispo y los Reyes Católicos, y buscar una conciliación post mortem entre tan decisivos personajes. Y esto sin duda porque don Alonso había sufrido una damnatio memoriae que debía doler a su sobrino y a aquellos que se beneficiaron de su generosidad.

La ruptura entre el arzobispo y los reyes pudo además tener consecuencias que desconocemos para Pero Guillén y su hijo Diego. Para entender este juego de facciones, alianzas y disputas, no se debe olvidar que el padre de Diego había estado dos veces en el bando equivocado, primero con don Álvaro, y luego con don Alonso. Parece que Diego Guillén quiere dejar muy clara su lealtad a la reina, y por eso le escribe un Panegírico. Su relación con Gómez Manrique, a quien dice querer servir, viene a confirmar la adhesión de Diego a Isabel de Castilla. Los Manrique estuvieron del lado de la hija de Juan II desde muy pronto. Jorge Manrique murió peleando contra las tropas de Juana la Beltraneja y su tío Gómez sirvió a Isabel desde sus tiempos de princesa. Pero el canónigo de Palencia no quiere tampoco olvidar sus deudas de gratitud. En cualquier caso, Guillén hijo escribe su Panegírico real para expresar su lealtad a la España de los Reyes Católicos, puestos por Dios en el trono para gloria de sus estados, como Diego no se cansa de declarar. Los hombres de la casa de Alonso Carrillo quedaron en una desairada posición cuando Isabel y Fernando se afianzaron en el poder, tras desertar el arzobispo de las filas isabelinas y pasarse al bando contrario. Es cierto que los reyes fueron generosos y ofrecieron amplio perdón tras la contienda, pero esto no libró de desamparo a quienes habían vivido bajo la protección liberal de don Alonso. Si Pero Guillén ya había muerto en este momento, no lo sabemos, pero su hijo, criado en la casa del arzobispo, bien pudo sufrir las consecuencias.

La carta arriba transcrita establece claramente una relación entre Diego Guillén y Gómez Manrique. Ya Henry Lang en 1908 se refiere a la existencia de un círculo literario en torno al noble ${ }^{71}$, del que Pero Guillén habría formado parte y con el que también estuvo relacionado su hijo Diego. John Cummins considera la posibilidad de que se trate de un círculo literario que girase en torno a la casa de Alonso Carrillo, arzobispo de Toledo. Defiende su idea con textos de Hernando del Pulgar y del propio Pero Guillén. Los estrechos vínculos que unieron a Carrillo, Manrique y Pero Guillén resultan evidentes. El pro-

${ }^{71}$ Henry R. Lang, «The so-called Cancionero de Pero Guillén de Segovia», Revue Hispanique, 19, 1908, pág. 52. 
blema, según J. Cummins, es la falta de datos que enlacen al arzobispo con los otros poetas claramente relacionados con Gómez Manrique y Pero Guillén ${ }^{72}$. Moreno Hernández aporta más noticias que vienen a reforzar la idea de la existencia en la corte de Carrillo de un círculo intelectual, que vendría a ser en parte continuación del círculo del Marqués de Santillana, en el que Gómez Manrique se formó ${ }^{73}$. Diversos testimonios y referencias permiten sostener que una parte de los autores asociados a Manrique y Guillén en los manuscritos formaban parte de este círculo intelectual. Se trata de Rodrigo Cota, Antón de Montoro, Juan Poeta o de Valladolid, Juan de Mazuela, Álvarez Gato y Pero Díaz de Toledo, este último como enlace directo con el círculo de Santillana, de quien fue capellán. Alonso de Palencia, Jorge Manrique y Sancho de Rojas podrían añadirse también. Los dos primeros son nombrados como miembros de este grupo por Francisco Vidal González ${ }^{74}$ y el segundo por Miguel Ángel Pérez Priego ${ }^{75}$. Varios de ellos fueron además de poetas, notables traductores. Ya hemos tratado de Diego Guillén, pero merecen también ser destacados Alonso de Palencia y Pero Díaz de Toledo. Palencia vertió, entre otras obras, las Vidas de Plutarco y a Flavio Josefo, y, muy consciente de su labor como traductor, se interesó por el vocabulario y los problemas léxicos ${ }^{76}$. Pero Díaz de Toledo por su parte romanceó el Fedro, a partir de la versión latina de Leonardo Bruni, y a San Basilio y Séneca ${ }^{77}$. El patrocinio que don Alonso Carrillo pudo ejercer sobre esta labor de traducción es un asunto que merece ser investigado con detenimiento.

Este grupo bajo el mecenazgo de Carrillo debió ir formándose poco después de la muerte de Santillana en 1458, coincidiendo con el inicio de las desavenencias entre Enrique IV y parte de la nobleza, con el arzobispo como miembro destacado de los contrarios a Enrique. Moreno Hernández considera

72 John G. Cummins, «Pero Guillén de Segovia y el ms. 4114», Hispanic Review, 41, 1973, pág. 31.

${ }^{73}$ Carlos Moreno Hernández, op. cit., págs. 33 y 70-71.

74 Francisco Vidal González, op. cit., pág. 24.

75 Miguel Ángel Pérez Priego, ed., Obra lírica de Juan de Mena, Madrid, Alhambra, 1979, pág. 257.

${ }^{76}$ Sobre Alfonso de Palencia y su obra sigue siendo muy útil el trabajo de Antonio Paz y Meliá, El cronista Alfonso de Palencia: su vida y sus obras, Madrid, Imp. Revista de Archivos, 1914. Sobre algunos aspectos particulares de su producción véanse: John M. Hill, ed., Universal vocabulario de Alfonso de Palencia. Registro de voces españolas internas, Madrid, Real Academia Española, 1957; Javier Durán Barceló, «Alfonso de Palencia, traductor de Flavio Josefo» en Proyección histórica de España en sus tres culturas: Castilla y León, América y el Mediterráneo, Valladolid, Junta de Castilla y León, 1993. Contiene una introducción general bastante completa y actualizada pese a estar dedicado a Palencia como historiador el reciente estudio: Marie Madelaine Dubrasquet Pardo, Alonso de Palencia, historien: études sur les Gesta Hispaniensia, Villeneuve d'Ascp, Presses Universitaires du Septentrion, 2003.

${ }^{77}$ Nicholas G. Round, ed., Libro llamado Fedron. Plato's Phaedro traslated by Pero Díaz de Toledo (ms. Madrid, B.N. Vitr. 17, 4), London-Madrid, Tamesis, 1993. 
que debió existir hasta 1474, fecha en que muere el rey. En esta época es cuando Carrillo retira su apoyo a Isabel y Fernando. Gómez Manrique, a pesar de su vieja y estrecha relación con don Alonso, mantiene su lealtad a los reyes, cuando el irascible arzobispo rompe con ellos ${ }^{78}$, aunque hasta el último momento intentó resolver sus diferencias ${ }^{79}$. No sabemos con certeza cuál fue la actitud de Pero Guillén y su hijo Diego en este caso. Las noticias sobre la vida del padre se pierden en 1475 , pero es fácil suponer que la familia se mantuvo leal al arzobispo hasta el final. Gómez Manrique era un noble y, aunque no era muy rico, pertenecía por nacimiento a una de las más rancias familias del reino y, por matrimonio, a una de las más poderosas, los Mendoza, así que bien podía prescindir de Carrillo; no así los Guillén, que le debían haber salido de la pobreza extrema en que vivían. Podemos considerar los Panegíricos de Diego Guillén como parte de la producción poética que se genera en torno a Carrillo y Gómez Manrique, y sus traducciones como una consecuencia de los vínculos que nuestro autor estableció en este círculo en que alientan ya las novedades del humanismo.

78 Juan de Mata Carriazo, ed., Crónica de los Reyes Católicos de Hernando del Pulgar, Madrid, Espasa-Calpe, 1943, pág. 335.

79 Manuel Gómez Moreno y Juan Mata Carriazo, op. cit., pág. 46. 